\title{
ANALISIS NORMA SUBYEKTIF, SIKAP TERHADAP PERILAKU DAN PERSEPSI KENDALI PERILAKU TERHADAP NIAT KARYAWAN MELAKUKAN TINDAKAN WHISTLEBLOWING
}

\author{
Putu Nuniek Hutnaleontina ${ }^{1)}$ \\ I Wayan Sudiana ${ }^{2}$ \\ Ni Putu Widya Astuti ${ }^{3)}$ \\ 1,2,3 Universitas Hindu Indonesia, e-mail: putununiek89@unhi.ac.id
}

\begin{abstract}
The purpose of this study was to examine the factors that influence employee intention to conduct whistleblowing actions based on the Theory of Planned Behavior (TPB) proposed by Ajzen and Fishben (1988). The variables used in this study are subjective norms, attitudes toward behavior and perceptions of behavior control as independent variables and the intention to conduct whistleblowing as the dependent variable. This research was conducted at the Tabanan District Attorney. The number of samples taken was 65 employees, with saturated sampling method (census). Data collection was carried out through interviews and questionnaires. The analysis technique used is multiple linear regression. This analysis is used to calculate the magnitude of the influence of subjective norms, attitudes toward behavior and perceptions of behavioral control on the intention to conduct whistleblowing actions. The results of this study state that subjective norms have a significant effect on employee intention to conduct whistleblowing actions. In addition, attitudes towards behavior also have a significant effect on employees' intention to conduct whistleblowing actions. Perceptions of behavioral control also have a significant effect on employee intentions to carry out whistleblowing actions.
\end{abstract}

\section{Keywords: Subjective Norms, Attitudes to Behavior, Perception of Behavioral Control, Whistleblowing}

\section{PENDAHULUAN}

Perekonomian yang semakin maju dan berkembang, diwarnai pula dengan berkembangnya praktik kejahatan perekonomian dalam berbagai macam bentuknya. Praktik-praktik kejahatan tersebut dalam akuntansi disebut sebagai kecurangan atau fraud. Fraud secara umum diartikan sebagai kecurangan atau penipuan dengan tujuan untuk memperoleh keuntungan secara material maupun non material. Ada juga istilah lain yang sering digunakan untuk menggambarkan suatu jenis fraud, yaitu kejahatan kerah putih atau whitecollar crime. 
Banyak kasus kecurangan yang terjadi di luar negeri maupun di Indonesia. Kasus Enron di Amerika yang terjadi pada tahun 2001, merupakan contoh bentuk kecurangan di pasar modal dengan melakukan manipulasi laporan keuangan. Manipulasi tersebut disebabkan karena adanya keinginan perusahaan supaya sahamnya tetap diminati oleh investor. Kasus Enron tersebut menyebabkan menurunnya harga saham secara drastis pada bursa efek di Amerika, Eropa dan Asia. Di Indonesia misalnya, kasus Gayus Tambunan, pegawai Direktorat Jendral Pajak yang terlibat dalam kasus pencucian uang dan penggelapan pajak dan kasus suap wisma atlet oleh anggota DPR, Angelina Sondakh (Sumber: suaramerdeka.com, diakses 30 Juli 2015).

Sistem pelaporan kecurangan di Indonesia sudah mulai dikembangkan oleh beberapa lembaga negara seperti Komisi Pemberantasan Korupsi (KPK), Pusat Pelaporan dan Analisis Transaksi Keuangan (PPATK), Ombudsman, Komisi Nasional Hak Asasi Manusia (Komnas HAM), Komisi Yudisial (KY), Komisi Kepolisian Nasional (Kompolnas), dan Komisi Kejaksaan. Sedangkan Lembaga Perlindungan Saksi dan Korban masih dalam tahap pembangunan sistem. Beberapa perusahaan swasta dan BUMN sudah membangun dan menerapkan sistem whistleblowing, diantaranya Pertamina, United Tractors, Sinar Mas, dan sebagainya, (LPSK, 2011).

Istilah whistleblower telah populer dan menarik perhatian dunia, karena banyak perusahaan besar yang melakukan kecurangan dan akhirnya terungkap melalui peran whistleblower. Banyak nama yang tercatat sebagai whistleblower atau orang yang melaporkan kecurangan atau pelanggaran. LPSK (2011) menyebutkan beberapa contoh, misalnya Sherron Watkins (kasus manipulasi laporan keuangan perusahaan Enron, Jeffrey Wigand (praktik manipulasi kadar nikotin rokok), Cynthia Cooper (kasus kecurangan perusahaan Worldcom), Komisaris Jendral Susno Duadji (kasus penggelapan pajak dan 
pencucian uang Gayus Tambunan), Agus Condro (kasus suap pemilihan Deputi Gubernur Senior Bank Indonesia) dan Vincentius Amin Sutanto (kasus skandal manipulasi pajak Sukanto Tanoto).

Berdasarkan hasil survey lapangan dan wawancara masih banyak karyawan khususnya karyawan di Kejaksaan Negeri Tabanan yang melalukan kecurangan dalam melaksanakan tugasnya sebagai pelayan masyarakat. Salah satunya, para karyawan sering meminta imbalan jasa kepada masyarakat atas jasa yang mereka berikan padahal pelayanan yang mereka lakukan tersebut sudah menjadi kewajiban mereka sebagai pelayan masyarakat. Selain itu, terjadi juga kecurangan pengeluaran kas seperti menciptakan rekanan fiktif melalui perusahaaan papan nama (shell company), meninggikan biaya (overslated expense) dari yang sebenarnya dikeluarkan sehingga penggantian biaya yang diterima lebih tinggi dari yang benar-benar dikeluarkan serta penggantian biaya atas biaya fiktif (fictitious expense schemes). Sedangkan rekan kerja mereka seolah-olah membiarkan kecurangan tersebut. Sehingga kecurangan seperti itu sudah biasa dilakukan oleh karyawan pemerintahan dan menjadi kebiasaan. Karena masih terbatasnya penelitian akuntansi dalam bidang etika mendorong peneliti untuk menguji kembali faktor-faktor yang mempengaruhi niat seseorang untuk melakukan whistleblowing khususnya pada Kejaksaan Negeri Tabanan dengan menerapkan Theory of Planned Behaviour (TPB). Theory of Planned Behaviour (TPB) terdiri dari tiga (3) bagian yaitu norma subyektif (subjective norms), sikap terhadap perilaku (attitude toward behaviour) dan persepsi kendali perilaku (perceived behavioral control) sekaligus menjadi variabel independen dalam penelitian ini. Norma subyektif dianggap dapat mempengaruhi niat karyawan untuk melakukan tindakan pelaporan kecurangan (whistleblowing) karena norma subyektif merupakan dukungan dari 
orang-orang yang dianggap penting yang berada di sekitar calon pelaku yang dalam hal ini adalah karyawan Kejaksaan Negeri Tabanan.

Penelitian ini akan menguji faktor-faktor yang mempengaruhi niat karyawan dalam melakukan whistleblowing berdasarkan theory of planned bahavior (TPB). Penelitian tentang whistleblowing pada karyawan di instansi pemerintahan sangat penting untuk dilakukan karena posisi mereka sebagai pelayan masyarakat serta kinerja karyawan pula yang menentukan berhasil tidaknya instansi tersebut mencapai tujuannya. Pengetahuan mengenai faktor-faktor yang mempengaruhi niat karyawan untuk melakukan whistleblowing dapat dijadikan sebagai informasi penting dalam upaya mencetak karyawan yang beretika tinggi dan mewujudkan pemerintahan yang transparan. Berdasarkan uraian di atas, maka penelitian ini diberi judul "Analisis Norma Subyektif, Sikap Terhadap Perilaku dan Persepsi Kendali Perilaku Terhadap Niat Karyawan melakukan Tindakan Whistleblowing (Studi kasus pada Karyawan Kejaksaan Negeri Tabanan)”.

Penelitian ini menunjukkan bahwa norma subyektif berpengaruh terhadap niat mahasiswa akuntansi untuk melakukan whistleblowing. Arah koefisien regresi X1 (persepsi tentang norma subyektif) positif berarti ketika nilai variabel penilaian tentang norma subyektif meningkat maka akan memberikan kenaikan pada variabel niat. Hal ini berarti bahwa semakin baik penilaian tentang norma subyektif terhadap whistleblowing maka niat mahasiswa akuntansi untuk melakukan whistleblowing akan semakin tinggi. Hasil penelitian ini menunjukkan bahwa penilaian tentang norma subyektif memiliki pengaruh yang signifikan positif terhadap niat mahasiswa akuntansi melakukan whistleblowing. Hipotesis penelitian dapat dirumuskan sebagai berikut:

\section{H1: Norma subyektif berpengaruh positif terhadap niat melakukan whistleblowing.}

Fishbein dan Ajzen (1980) dalam artikelnya yang berjudul Understanding 
attitudes and predicting social Behavior mengatakan bahwa "Faktor penentu yang pertama adalah faktor kepribadian yaitu penilaian seseorang baik positif maupun negatif dalam melakukan suatu tindakan perilaku. O'Leary dan Cotter (2000) di dalam penelitiannya yang berjudul The Ethics of Final Year Accountancy Students. A Tri-national Comparation, penelitian ini mengenai sikap terhadap perilaku mahasiswa akuntansi tingkat akhir di Irlandia dan Australia dengan hasil persentase lebih dari $50 \%$ mahasiswa Australia dan kurang dari $50 \%$ mahasiswa Irlandia bersedia melakukan whistleblowing. Arah koefisien regresi X2 (sikap terhadap perilaku) positif berarti ketika nilai variabel sikap terhadap perilaku meningkat maka akan memberikan kenaikan pada variabel niat. Hal ini berarti bahwa semakin baik penilaian tentang sikap terhadap perilaku seseorang terhadap whistleblowing maka niat mahasiswa akuntansi untuk melakukan whistleblowing akan semakin tinggi. Hipotesis penelitian dapat dirumuskan sebagai berikut:

\section{H2: Sikap terhadap perilaku berpengaruh positif terhadap niat melakukan whistleblowing.}

Sulistomo (2012) di dalam penelitiannya yang berjudul persepsi mahasiswa akuntansi terhadap pelaporan kecurangan (studi empiris mahasiswa akuntansi di Undip dan UGM). Pada penelitian ini menunjukkan bahwa persepsi kendali perilaku berpengaruh terhadap niat mahasiswa akuntansi untuk melakukan whistleblowing. Arah koefisien regresi X3 (persepsi kendali perilaku) positif berarti ketika nilai dari persepsi kendali perilaku meningkat maka nilai dari niat juga akan meningkat. Jadi persepsi kendali perilaku ini dihasilkan dari persepsi seseorang terhadap suatu perilaku yang dilakukan, dimana seseorang yakin bahwa persepsi yang dimilikinya merupakan hasil dari kontrol dirinya sendiri mengenai persepsi perilaku tersebut. Hipotesis penelitian dapat dirumuskan sebagai berikut: 


\section{H3: Persepsi kendali perilaku berpengaruh positif terhadap niat melakukan whistleblowing.}

\section{METODE PENELITIAN}

Pendekatan yang digunakan dalam penelitian ini adalah kausal komparatif. Penelitian kausal komparatif adalah tipe penelitian dengan karakteristik masalah berupa hubungan sebab-akibat antara dua variabel atau lebih, dan peneliti dapat mengidentifikasi fakta atau peristiwa sebagai variabel yang dipengaruhi (variabel dependen) dan melakukan penyelidikan terhadap variabel yang mempengaruhi (variabel independen).

Teknik pengambilan sampel dalam penelitian ini menggunakan teknik sampling jenuh (sensus) karena dalam penelitian ini peneliti mengukur tingkat perilaku seseorang dan persepsi seseorang terhadap suatu tindakan atau perilaku sehingga untuk mendapatkan hasil yang lebih valid. Sampel dari penelitian ini berjumlah 65 orang yang terdiri dari Pegawai Negeri Sipil (PNS) golongan II, golongan III dan golongan IV. Pegawai Negeri Sipil (PNS) di Kejaksaan Negeri Tabanan menjabat sebagai Jaksa sebanyak 30 orang dan sebagai staff berjumlah 35 orang.

Teknik analisis data yang digunakan pada penelitian ini adalah Teknik analisis regresi berganda (multiple regession analysis). Model regresi berganda bertujuan untuk memprediksi besar variabel terikat (dependen) dengan menggunakan variabel bebas (independen) yang sudah diketahui besarnya. Teknik analisis ini digunakan untuk mengetahui variabel dependen (Y) yaitu niat karyawan melakukan whistleblowing, sedangkan variabel independennya terdiri atas: norma subyektif $\left(\mathrm{X}_{1}\right)$, sikap terhadap perilaku $\left(\mathrm{X}_{2}\right)$ dan persepsi kendali perilaku $\left(\mathrm{X}_{3}\right)$. 


\section{HASIL DAN PEMBAHASAN}

Dalam penelitian ini karakteristik responden penelitian pada pegawai Kejaksaan Negeri Tabanan dilihat dari beberapa kriteria, yaitu jenis kelamin, umur, tingkat pendidikan dan pangkat / golongan.

Tabel 1.

Karakteristik Responden Menurut Jenis Kelamin

\begin{tabular}{ccc}
\hline Jenis Kelamin & $\begin{array}{c}\text { Jumlah } \\
\text { (Orang) }\end{array}$ & $\begin{array}{c}\text { Persentase } \\
(\mathbf{\%})\end{array}$ \\
\hline Laki-laki & 28 & 43,08 \\
Perempuan & 37 & 56,92 \\
Total & $\mathbf{6 5}$ & $\mathbf{1 0 0}$ \\
\hline Umur & Jumlah & Persentase \\
& $($ Orang) & 10,78 \\
\hline$<25$ Tahun & 7 & 75,38 \\
25-40 Tahun & 49 & 13,84 \\
$>40$ Tahun & 9 & $\mathbf{1 0 0}$ \\
Total & $\mathbf{6 5}$ & Persentase \\
Tingkat Pendidikan & Jumlah & $16)$ \\
\hline SMA & (Orang) & 49,23 \\
Diploma & 11 & 33,85 \\
Sarjana & 32 & $\mathbf{1 0 0}$ \\
Total & 22 & Persentase \\
Pangkat & $\mathbf{6 5}$ & $(\mathbf{\%})$ \\
(Golongan) & Jumlah & 27,69 \\
Golongan II & $($ Orang) & 69,23 \\
Golongan III & 18 & 3,08 \\
Golongan IV & 45 & $\mathbf{1 0 0}$ \\
Total & 2 & \\
& $\mathbf{6 5}$ &
\end{tabular}

Sumber: Data primer diolah, 2018

Berdasarkan tabel 1 di atas dapat diketahui bahwa jenis kelamin pegawai Kejaksaan Negeri Tabanan sebagian besar adalah perempuan, karena terdapat 37orang atau 56,92\% dari jumlah keseluruhan responden. Sedangkan jenis kelamin laki-laki terdapat 28 orang atau $43,08 \%$ dari jumlah keseluruhan responden.

Tabel 1 menunjukkan bahwa sebagian besar responden memiliki umur 25-40 tahun yaitu sebanyak 49 orang atau 75,38\% dari keseluruhan jumlah responden. Responden yang berumur $<25$ tahun berjumlah 7 orang atau $10,78 \%$ dari jumlah keseluruhan responden dan 
responden yang berumur $>40$ tahun berjumlah 9 orang atau $13,84 \%$ dari jumlah keseluruhan responden.

Berdasarkan tabel 1 dapat diketahui bahwa sebagian besar tingkat pendidikan karyawan Kejaksaan Negeri Tabanan adalah Diploma berjumlah 32 orang atau 49,23\%. Karyawan tingkat pendidikannya Sarjana berjumlah 22 orang atau 33,85\%. Sedangkan karyawan yang tingkat pendidikannya hingga SMA berjumlah 11 orang atau 16,92\%.

Berdasarkan tabel 1 di atas dapat disimpulkan bahwa sebagian besar pangkat (golongan) karyawan Kejaksaan Negeri Tabanan adalah golongan III yaitu berjumlah 45 orang atau $69,23 \%$. Karyawan golongan II berjumlah 18 orang atau 27,69\%. Sedangkan karyawan golongan IV berjumlah 2 orang atau 3,08\%.

Tabel 2.

Hasil Uji Validitas Variabel Norma Subyektif

\begin{tabular}{cccc}
\hline No & Indikator & Koefisien Korelasi & Keterangan \\
\hline 1 & $\mathrm{X} 1.1$ & 0.977 & Valid \\
2 & $\mathrm{X} 1.2$ & 0.953 & Valid \\
3 & $\mathrm{X} 1.3$ & 0.947 & Valid \\
\hline \multicolumn{2}{l}{ Sumber: }
\end{tabular}

Berdasarkan tabel 2 diketahui bahwa seluruh indikator dalam variabel norma subyektif memiliki koefisien korelasi yang lebih besar dari 0,30. Jadi dapat disimpulkan bahwa seluruh indikator telah memenuhi syarat validitas data.

Tabel 3.

Hasil Uji Validitas Variabel Sikap Terhadap Perilaku

\begin{tabular}{cccc}
\hline No & Indikator & Koefisien Korelasi & Keterangan \\
\hline 1 & $\mathrm{X} 2.1$ & 0.872 & Valid \\
2 & $\mathrm{X} 2.2$ & 0.891 & Valid \\
3 & $\mathrm{X} 2.3$ & 0.857 & Valid \\
4 & $\mathrm{X} 2.4$ & 0.865 & Valid \\
\hline
\end{tabular}

Sumber: Data primer diolah, 2018

Berdasarkan tabel 3 diketahui bahwa seluruh indikator dalam variabel sikap terhadap perilaku memiliki koefisien korelasi yang lebih besar dari 0,30. Jadi dapat disimpulkan bahwa seluruh indikator telah memenuhi syarat validitas data. 
Tabel 4.

Hasil Uji Variabel Persepsi Kendali Perilaku

\begin{tabular}{cccc}
\hline No & Indikator & Koefisien Korelasi & Keterangan \\
\hline 1 & X3.1 & 0.892 & Valid \\
2 & X3.2 & 0.831 & Valid \\
3 & X3.3 & 0.784 & Valid \\
4 & X3.4 & 0.862 & Valid \\
5 & X3.5 & 0.849 & Valid \\
6 & X3.6 & 0.883 & Valid \\
7 & X3.7 & 0.858 & Valid \\
8 & X3.8 & 0.873 & Valid \\
9 & X3.9 & 0.796 & Valid \\
10 & X3.10 & 0.875 & Valid \\
\hline
\end{tabular}

Sumber: Data primer diolah, 2018

Berdasarkan tabel 4. diketahui bahwa seluruh indikator dalam variabel persepsi kendali perilaku memiliki koefisien korelasi yang lebih besar dari 0,30. Jadi dapat disimpulkan bahwa seluruh indikator telah memenuhi syarat validitas data.

Tabel 5.

Hasil Uji Validitas Variabel Niat untuk Melakukan Tindakan Whistleblowing

\begin{tabular}{cccc}
\hline No & Indikator & Koefisien Korelasi & Keterangan \\
\hline 1 & Y1 & 0.918 & Valid \\
2 & Y2 & 0.898 & Valid \\
3 & Y3 & 0.903 & Valid \\
\hline
\end{tabular}

Sumber: Data primer diolah, 2018

Berdasarkan tabel 5 diketahui bahwa seluruh indikator dalam variabel niat untuk melakukan tindakan whistleblowing memiliki koefisien korelasi yang lebih besar dari 0,30. Jadi dapat disimpulkan bahwa seluruh indikator telah memenuhi syarat validitas data.

Tabel 6.

Hasil Uji Reliabilitas

\begin{tabular}{cccc}
\hline No & Variabel & Nilai Alpha Cronbach & Keterangan \\
\hline 1 & Norma Subyektif & 0.956 & Reliabel \\
2 & Sikap Terhadap Perilaku & 0.893 & Reliabel \\
3 & Persepsi Kendali Perilaku & 0.956 & Reliabel \\
4 & Niat Melakukan Whistleblowing & 0,891 & Reliabel \\
\hline Sumber: &
\end{tabular}

Sumber: Data primer diolah, 2018

Tabel 6 menunjukkan Alpha Cronbach semua variable diatas 0,60 sehingga dapat disimpulkan bahwa semua variabel telah memenuhi syarat reliabilitas data. 
Tabel 7.

Hasil Uji Normalitas

\begin{tabular}{llr}
\hline & & Unstandardized Residual \\
\hline $\mathrm{N}$ & & 65 \\
Normal Parameters ${ }^{\mathrm{a}, \mathrm{b}}$ & Mean & .0000000 \\
& Std. Deviation & .82073653 \\
Most Extreme Differences & Absolute & .084 \\
& Positive & .053 \\
& Negative & -.084 \\
Test Statistic & & .084 \\
Asymp. Sig. (2-tailed) & & $.200^{\mathrm{c}, \mathrm{d}}$ \\
\hline
\end{tabular}

Sumber: Data primer diolah, 2018

Berdasarkan output SPSS diperoleh nilai Asymp. Sig (2-tailed) sebesar 0,200 yang lebih besar dari 0,05. Hal ini berarti residual data berdistribusi normal.

Tabel 8. Hasil Uji Multikolinearitas

\begin{tabular}{lcc}
\hline & \multicolumn{3}{c}{ Collinearity Statistics } \\
Model & Tolerance & VIF \\
\hline norma subjektif & .544 & 1.840 \\
sikap terhadap perilaku & .466 & 2.146 \\
persepsi kendali prilaku & .572 & 1.749 \\
\hline Sumber: Data primer diolah, 2018 & &
\end{tabular}

Tabel 8 menunjukkan bahwa nilai tolerance variabel norma subyektif sebesar 0,544, sikap terhadap perilaku sebesar 0,466 , persepsi kendali perilaku sebesar 0,572 dan variance inflation factor (VIF) variabel norma subyektif sebesar 1,840, sikap terhadap perilaku sebesar 2,146, persepsi kendali perilaku sebesar 1,749 sehingga tidak ada variabel bebas yang nilai tolerance kurang dari 0,1 atau variance inflation factor (VIF) lebih dari 10, maka disimpulkan tidak ada multikolinearitas antara variabel bebas dalam model regresi.

Tabel 9.

Hasil Uji Heteroskedastisitas

\begin{tabular}{lcccc}
\hline & Unstandardized & Standardized & & \\
Model & Coefficients & Coefficients & t & Sig.
\end{tabular}




\begin{tabular}{llllrrr} 
& \multicolumn{1}{c}{ B } & Std. Error & Beta & & \\
\hline $1 \quad$ (Constant) & 1.603 & .336 & & 4.775 & .000 \\
& norma subjektif & -.040 & .033 & -.198 & -1.213 & .230 \\
& sikap terhadap perilaku & -.005 & .028 & -.033 & -.186 & .853 \\
& persepsi kendali prilaku & -.011 & .010 & -.164 & -1.031 & .307 \\
\hline \multicolumn{2}{l}{ Sumber: Data primer diolah, 2018 } & & & & &
\end{tabular}

Berdasarkan hasil pengujian yang ditunjukkan pada Tabel 9 tersebut dapat dilihat bahwa nilai signifikansi dari variabel norma subyektif sebesar 0,230 , variabel sikap terhadap perilaku sebesar 0,853, variabel persepsi kendaliperilaku sebesar 0,307. Jadi dapat disimpulkan bahwa ketiga variabel independen memiliki nilai sig $>0,05$ yang berarti bahwa tidak terjadi masalah heteroskedastisitas pada model regresi.

Tabel 10.

\section{Hasil Analisis Regresi Linear Berganda}

\begin{tabular}{|c|c|c|c|c|c|c|c|c|}
\hline \multirow{2}{*}{\multicolumn{2}{|c|}{ Model }} & \multicolumn{2}{|c|}{$\begin{array}{c}\text { Unstandardized } \\
\text { Coefficients } \\
\text { Std. }\end{array}$} & \multicolumn{2}{|l|}{$\begin{array}{c}\text { Standardized } \\
\text { Coefficients }\end{array}$} & \multicolumn{3}{|c|}{$\begin{array}{l}\text { Collinearity } \\
\text { Statistics } \\
\text { Tolera }\end{array}$} \\
\hline & & B & Error & Beta & $\mathrm{t}$ & Sig. & nce & VIF \\
\hline \multirow[t]{4}{*}{1} & (Constant) & 4.912 & .619 & & 7.938 & .000 & & \\
\hline & $\mathrm{X} 1$ & .302 & .060 & .435 & 5.019 & .000 & .544 & 1.840 \\
\hline & $\mathrm{X} 2$ & .195 & .051 & .358 & 3.826 & .000 & 466 & 2.146 \\
\hline & X3 & .046 & .019 & .205 & 2.427 & .018 & .572 & 1.749 \\
\hline
\end{tabular}

Dari perhitungan di atas diperoleh nilai:

$$
\begin{array}{lll}
\alpha & =4,912 \\
\beta 1 & =0,302 \\
\beta 2 & =0,195 \\
\beta 3 & =0,046
\end{array}
$$

Berdasarkan nilai $\alpha, \beta, \beta 2, \beta 3$, diperoleh persamaan garis regresi linear berganda antara norma subyektif, sikap terhadap perilaku dan persepsi kendali perilaku terhadap niat melakukan tindakan whistleblowing adalah :

$$
\mathrm{Y}=4,912+0,302 \mathrm{X} 1+0,195 \mathrm{X} 2+0,046 \mathrm{X} 3
$$


1. $\alpha=4,912$, artinya apabila tidak ada pengaruh dari variabel norma subyektif, sikap terhadap perilaku dan persepsi kendali perilaku yang dianggap bernilai konstan maka skor niat melakukan tindakan whistleblowing adalah sebesar 4,912.

2. $\beta 1=0,302$, artinya apabila sikap terhadap perilaku dan persepsi kendali perilaku dianggap konstan, maka meningkatnya skor norma subyektif (X1) sebesar satu satuan akan diikuti oleh meningkatnya skor niat melakukan tindakan whistleblowing (Y) sebesar 0,302 .

3. $\beta 2=0,195$, artinya apabila norma subyektif dan persepsi kendali perilaku dianggap konstan, maka meningkatnya skor sikap terhadap perilaku (X2) sebesar satu satuan akan diikuti oleh meningkatnya skor niat melakukan tindakan whistleblowing (Y) sebesar 0,195 .

4. $\beta 3=0,046$, artinya apabila norma subyektif dan sikap terhadap perilaku dianggap konstan, maka meningkatnya skor persepsi kendali perilaku (X3) sebesar satu satuan akan diikuti oleh meningkatnya skor niat untuk melakukan tindakan whistleblowing (Y) sebesar 0,046 .

Tabel 11.

\section{Koefisien Determinasi}

\begin{tabular}{lrrrr}
\hline Model & $\mathrm{R}$ & R Square & $\begin{array}{c}\text { Adjusted R } \\
\text { Square }\end{array}$ & $\begin{array}{c}\text { Std. Error of the } \\
\text { Estimate }\end{array}$ \\
\hline 1 & $.867^{\text {a }}$ & .751 & .739 & .84068 \\
\hline Sumber: Data primer diolah, 2018 & & &
\end{tabular}

Berdasarkan tabel 11 di atas dapat dilihat nilai $\mathrm{R}$ Square sebesar 0,751, artinya adalah bahwa pengaruh variabel independen terhadap variabel dependen adalah sebesar $75,1 \%$. Oleh karena itu, dapat disimpulkan bahwa sebesar 75,1\% niat melakukan tindakan whistleblowing dipengaruhi oleh variabel norma subyektif, sikap terhadap perilaku dan persepsi kendali perilaku. Sedangkan sisanya 24,9\% dijelaskan oleh variabel lain di luar 
variabel norma subyektif, sikap terhadap perilaku dan persepsi kendali perilaku yang dijelaskan dalam penelitian ini.

Tabel 12.

Uji Statistik F

\begin{tabular}{llrrrrr}
\hline Model & & Sum of Squares & Df & Mean Square & F & \multicolumn{1}{c}{ Sig. } \\
\hline 1 & Regression & 130.335 & 3 & 43.445 & 61.473 & $.000^{\mathrm{b}}$ \\
& Residual & 43.111 & 61 & .707 & & \\
& Total & 173.446 & 64 & & & \\
\hline
\end{tabular}

Sumber: Data primer diolah, 2018

Berdasarkan hasil pengujian ANOVA pada tabel 12 diperoleh nilai dengan signifikansi $0,000^{\mathrm{b}}<0,05$ ini berarti bahwa model regresi yang digunakan adalah layak.

Tabel 13.

Uji Statistik t

\begin{tabular}{|c|c|c|c|c|c|c|}
\hline \multirow[b]{2}{*}{ Model } & & \multicolumn{2}{|c|}{$\begin{array}{l}\text { Unstandardized } \\
\text { Coefficients }\end{array}$} & \multirow{2}{*}{$\begin{array}{c}\text { Standardized } \\
\text { Coefficients } \\
\text { Beta } \\
\end{array}$} & \multirow[b]{2}{*}{$\mathrm{t}$} & \multirow[b]{2}{*}{ Sig. } \\
\hline & & $\mathrm{B}$ & Std. Error & & & \\
\hline \multirow[t]{4}{*}{1} & (Constant) & 4.912 & .619 & & 7.938 & .000 \\
\hline & norma subjektif & .302 & .060 & .435 & 5.019 & .000 \\
\hline & $\begin{array}{l}\text { sikap terhadap } \\
\text { perilaku }\end{array}$ & .195 & .051 & .358 & 3.826 & .000 \\
\hline & $\begin{array}{l}\text { persepsi } \\
\text { kendali prilaku }\end{array}$ & .046 & .019 & .205 & 2.427 & .018 \\
\hline
\end{tabular}

Hasil perhitungan diperoleh $\mathrm{t}_{1}$-hitung adalah 5,019 dan nilai sig $0,000<0,05$ maka H0 ditolak atau H1 diterima, berarti memang benar ada pengaruh yang positif antara norma subyektif terhadap niat untuk melakukan tindakan whistleblowing.

Hasil perhitungan diperoleh $\mathrm{t}_{2}$-hitung adalah 3,826 dan nilai sig $0,000<0,05$ maka H0 ditolak atau $\mathrm{H} 2$ diterima, berarti memang benar ada pengaruh yang positif dan nyata (signifikan) antara sikap terhadap perilaku terhadap niat untuk melakukan tindakan whistleblowing. 
Hasil perhitungan diperoleh $\mathrm{t}_{3}$-hitung adalah 2,427 dan nilai sig 0,018 $<0,05$ maka H0 ditolak atau H3 diterima, berarti memang benar ada pengaruh yang positif dan nyata (signifikan) antara persepsi kendali perilaku terhadap niat untuk melakukan tindakan whistleblowing.

Pengaruh norma subyektif terhadap niat untuk melakukan tindakan whistleblowing menunjukkan hasil pengujian pengaruh variabel tersebut diperoleh $\mathrm{t}_{1}$-hitung 5,019 dengan signifikansi sebesar 0,000 dan koefisien regresi sebesar 0,302 dengan arah positif. Dengan demikian dapat disimpulkan bahwa norma subyektif memiliki pengaruh positif dan signifikan terhadap niat untuk melakukan tindakan whistleblowing, sehingga hipotesis pertama dalam penelitian ini diterima

Hasil penelitian ini memberikan makna bahwa semakin tinggi norma subyektif yang dimiliki oleh seseorang, maka semakin tinggi pula niat seseorang untuk melakukan tindakan whistleblowing karena semakin tinggi dukungan yang diberikan oleh kebanyakan orang yang penting baginya untuk melakukan tindakan whistleblowing maka semakin tinggi pula niat individu tersebut untuk melakukan tindakan whistleblowing tersebut.

Semakin banyak dukungan dari orang-orang yang penting (norma subyektif) bagi karyawan Kejaksaan Negeri Tabanan, maka semakin tinggi pula niat karyawan tersebut untuk melakukan tindakan whistleblowing. Dengan kata lain, norma subyektif atau dukungan dari orang-orang terdekat di sekitar karyawan merupakan faktor penting bagi karyawan untuk melakukan tindakan whistleblowing. Hasil penelitian ini sejalan dengan penelitian yang dilakukan oleh Sulistomo (2012) yang membuktikan bahwa norma subyektif berpengaruh terhadap intensi pegawai untuk mengadukan pelanggaran (whistleblowing). 
Pengaruh sikap terhadap perilaku terhadap niat untuk melakukan whistleblowing menunjukkan arah positif. Hasil pengujian pengaruh variabel tersebut diperoleh $\mathrm{t}_{2}$-hitung sebesar 3,826 dengan signifikansi sebesar 0,000 dengan koefisien regresi sebesar 0,195 dengan arah positif. Dengan demikian dapat disimpulkan bahwa sikap terhadap perilaku memiliki pengaruh positif dan signifikan terhadap niat seseorang untuk melakukan tindakan whistleblowing. Sehingga hipotesis kedua yang diajukan dalam penelitian ini diterima.

Hasil penelitian ini memberikan makna bahwa semakin tinggi sikap terhadap perilaku seseorang, maka semakin tinggi pula niat seseorang untuk melakukan tindakan whistleblowing, atau dengan kata lain semakin positif penilaian seseorang terhadap perilaku whistleblowing, maka semakin tinggi pula niat individu tersebut untuk melakukannya. Dapat dikatakan bahwa karyawan Kejaksaan Negeri Tabanan melakukan perilaku whistleblowing karena mereka meyakini bahwa perilaku tersebut dapat memberikan hasil yang positif.

Pengaruh persepsi kendali perilaku terhadap niat untuk melakukan tindakan whistleblowing menunjukkan arah positif. Hasil pengujian pengaruh variabel tersebut diperoleh t3-hitung sebesar 2,427 dengan signifikansi sebesar 0,018 dan koefisien regresi sebesar 0,046 dengan arah positif. Dengan demikian dapat disimpulkan bahwa persepsi kendali perilaku memiliki pengaruh positif dan signifikan terhadap niat untuk melakukan tindakan whistleblowing. Sehingga hipotesis ketiga yang diajukan dalam penelitian ini diterima.

Hasil penelitian ini menunjukkan semakin tinggi persepsi kendali perilaku seseorang maka semakin tinggi pula niat individu tersebut untuk melakukan tindakan whistleblowing atau dengan kata lain, karyawan Kejaksaan Negeri Tabanan memiliki niat untuk 
melakukan whistleblowing ketika mereka memiliki persepsi bahwa tindakan whistleblowing tersebut mudah untuk ditunjukkan atau dilakukan, karena adanya hal-hal yang mendukung perilaku whistleblowing seperti identitas yang dirahasiakan atau organisasi menawarkan hadiah karena telah melakukan whistleblowing.

\section{SIMPULAN}

Berdasarkan uraian pembahasan yang diuraikan pada bab sebelumnya, maka kesimpulan yang berkaitan dengan norma subyektif, sikap terhadap perilaku dan persepsi kendali perilaku terhadap niat untuk melakukan tindakan whistleblowing dalam penelitian ini adalah sebagai berikut: 1). Berdasarkan hasil pengujian diperoleh nilai $\mathrm{t}_{1}$-hitung adalah sebesar 5,019 dengan signifikansi sebesar 0,000 yang berarti variabel norma subyektif memiliki pengaruh positif dan signifikan terhadap niat untuk melakukan tindakan whistleblowing. Semakin tinggi dukungan orang terdekat maka semakin tinggi pula niat individu tersebut untuk melakukan tindakan pelaporan kecurangan (whistleblowing). Hasil penelitian ini sejalan dengan penelitian Erwan Suyono (2014); 2). Berdasarkan hasil pengujian diperoleh nilai $t_{2}$-hitung adalah sebesar 3,826 dengan signifikansi sebesar 0,000 yang berarti variabel sikap terhadap perilaku memiliki pengaruh positif dan signifikan terhadap niat untuk melakukan tindakan whistleblowing. Semakin positif penilaian seseorang terhadap perilaku whistleblowing, maka semakin tinggi pula niat individu tersebut untuk melakukannya. Hasil penelitian ini sejalan dengan hasil penelitian Arum Pusparani (2015); 3). Berdasarkan hasil pengujian diperoleh nilai $t_{3}$-hitung adalah sebesar 2,427 dengan signifikansi sebesar 0,018 yang berarti variabel persepsi kendali perilau memiliki pengaruh positif dan signifikan terhadap niat untuk melakukan tindakan whistleblowing. Semakin tinggi persepsi karyawan bahwa tindakan pelaporan kecurangan (whistleblowing) mudah untuk dilakukan, maka semakin tinggi pula niat karyawan untuk 
melakukan tindakan tersebut. Hasil Penelitian ini sejalan dengan penelitian Melissa Fitri Dwi Handika (2017).

Saran-saran yang dapat diberikan oleh peneliti bagi pihak-pihak yang berkepentingan dalam penelitian ini yaitu: 1). Bagi pemerintah Kejaksaan Negeri Tabanan perlu memberikan perhatian dan dukungan lebih bagi karyawan yang telah berani melakukan tindakan pelaporan kecurangan, sehingga karyawan lain ingin meniru tindakan tersebut. Diharapkan pula tindakan tersebut dapat mewujudkan transparasi dalam organisasi sehingga terwujud kinerja yang baik yang dapat mendukung visi dan misi organisasi; 2). Bagi pemerintah Kejaksaan Negeri Tabanan hendaknya memberikan reward dan lebih sering memberikan pengarahan kepada karyawannya mengenai sistem pelaporan kecurangan, sehingga karyawan semakin menganggap sistem pelaporan kecurangan merupakan tindakan yang positif dan para karyawan akhirnya memiliki niat yang tinggi untuk melakukan tindakan whistleblowing; 3). Pemerintah Kejaksaan Negeri Tabanan hendaknya membuatkan sistem untuk melakukan tindakan whistleblowing yang mudah dan tidak berbelit-belit sehingga karyawan yang ingin melakukan tindakan whistleblowing tidak dipersulit untuk melakukan tindakan tersebut. Jika karyawan sudah dipermudah untuk melakukan tindakan whistleblowing, maka niat untuk melakukan tindakan tersebut akan semakin tinggi.

\section{DAFTAR PUSTAKA}

Arens, A.A., Elder, R.J., \& Beasley,M.S.2008. Auditing dan Jasa Assurance: Pendekatan Terintegrasi. (Alih bahasa: Herman Wibowo). Jakarta: Penerbit Erlangga.

KNKG.2008. Pedoman Sistem Pelaporan Pelanggaran - SPP (Whistleblowing System WBS). Jakarta: KNKG.

Muhammad Dimar Alam. . "Persepsi Aparatur Pemerintahan dan Anggota Dewan Perwakilan Rakyat Daerah Kota Malang Terhadap Fraud dan Peran Whistleblowing sebagai Upaya Pencegahan dan Pendeteksian Fraud". 
Romney, Marshall B. \& Steinbart, Paul John.2003. Accounting Information System, 9th Edition. New Jersey: Pearson Education Inc.

Sekretariat 3pK.2007. Modul Whistleblowing System. Jakarta: Kementerian Negara Pendayagunaan Aparatur Negara.

Sugiyono. (2013). Metode Penelitian Kuantitatif, Kualitatif R\&D. Bandung: Alfabeta.

Suharsimi Arikunto.2002. Prosedur Penelitian Suatu Pendekatan Praktek Edisi Revisi V. Jakarta: Rineka Cipta.

Transparency International.2013. Corruption Perception Index 2013. Diakses

pada tanggal 1 Juni2017 dari https://www.transparency.org/cpi2013/results

Wolfe, David T.and Dana R. Hermanson.2004. "The Fraud Diamond: Considering the Four Elements of Fraud". CPA Journal 74.12: 38-42.

Yunus Husein.2011. Etika Bisnis dan Tinjauan Peraturan Perundang-undangan: Memastikan Sektor Swasta Melaksanakan Program Anti Korupsi untuk Menciptakan Sistem Integritas Nasional. Forum Diskusi Fakultas Hukum Universitas Indonesia.

Zimbelman, Mark et al.2006. Fraud Examination, 3rd Edition. Mason: South-Western Cengage Learning. 